BMJ Nutrition,

Prevention \& Health

\title{
Sex and gender differences in childhood obesity: contributing to the research agenda
}

\author{
Bindra Shah (D) , ${ }^{1}$ Katherine Tombeau Cost, ${ }^{2}$ Anne Fuller, ${ }^{3,4}$ Catherine S Birken, ${ }^{3,4,5}$ \\ Laura N Anderson (1D) 1,5
}

\begin{abstract}
To cite: Shah B, Tombeau Cost K, Fuller A, et al. Sex and gender differences in childhood obesity: contributing to the research agenda. BMJ Nutrition, Prevention \& Health 2020;3:e000074. doi:10.1136/ bmjnph-2020-000074
\end{abstract}

${ }^{1}$ Health Research Methods, Evidence, and Impact, McMaster University, Hamilton, Ontario, Canada

${ }^{2}$ Neuroscience and Mental Health, SickKids Research Institute, Toronto, Ontario, Canada

${ }^{3}$ Department of Pediatrics, University of Toronto, Toronto, Ontario, Canada

${ }^{4}$ Paediatric Medicine, The Hospital for Sick Children, Toronto, Ontario, Canada ${ }^{5}$ Child Health Evaluative Sciences, Hospital for Sick Children Research Institute, Toronto, Ontario, Canada

Correspondence to Laura N Anderson, Health Research Methods, Evidence, and Impact, McMaster University, Hamilton, ON L8S 4L8, Canada;

LN.Anderson@mcmaster.ca

Received 27 March 2020 Revised 12 August 2020 Accepted 20 August 2020 Published Online First 9 September 2020

Check for updates

(c) Author(s) (or their employer(s)) 2020. Re-use permitted under CC BY-NC. No commercial re-use. See rights and permissions. Published by BMJ.

\section{ABSTRACT}

Childhood obesity is a major public health challenge and its prevalence continues to increase in many, but not all, countries worldwide. International data indicate that the prevalence of obesity is greater among boys than girls 5-19 years of age in the majority of high and upper middle-income countries worldwide. Despite this observed sex difference, relatively few studies have investigated sex-based and gender-based differences in childhood obesity. We propose several hypotheses that may shape the research agenda on childhood obesity. Differences in obesity prevalence may be driven by gender-related influences, such as societal ideals about body weight and parental feeding practices, as well as sex-related influences, such as body composition and hormones. There is an urgent need to understand the observed sex differences in the prevalence of childhood obesity; incorporation of sex-based and gender-based analysis in all childhood obesity studies may ultimately contribute to improved prevention and treatment.

The World Obesity Federation released the first Atlas of Childhood Obesity in 2019, presenting the country-specific prevalence of obesity by age groups and sex, and calculated risk scores for future obesity. ${ }^{1}$ The number of school-aged children and adolescents living with obesity is predicted to rise from 150 million worldwide to over 250 million by 2030. ${ }^{1}$ This extraordinary increase in childhood obesity will place a large burden on healthcare systems as the population ages. ${ }^{2}$ Childhood obesity is a strong risk factor for adult obesity and many other chronic diseases, including type 2 diabetes and cardiovascular disease. $^{2}$ Although not discussed in the Atlas, a stark difference in the prevalence of obesity by sex was reported across all age groups. Obesity prevalence estimates were defined according to WHO growth references and interpolated based on prior Bayesian hierarchical modelling that accounted for both within-country and within-region variability. ${ }^{3}$ As summarised in figure 1, among children 5-9 years of age, 123 of $188(65 \%)$ countries reported a greater prevalence of obesity for boys than girls. For children aged 10-19, this same trend was observed for $112(60 \%)$ countries. This trend existed in the vast majority of high income and upper middle-income countries, but was not observed among lower middle and low-income countries (figure 1). ${ }^{1}$ In 44 of $88(50 \%)$ of these high and upper middle-income countries, the prevalence of obesity in boys was almost two-fold greater than girls when comparing within age group, for example, Singapore, Denmark and Canada. ${ }^{1}$

The difference in prevalence of obesity for boys and girls has also been reported previously. For example, National Canadian data (2004-2013) consistently observed a higher prevalence of obesity in boys compared with girls aged 3-19. ${ }^{4}$ A two-fold higher prevalence of severe obesity in boys compared with girls aged 5-9 has also been observed in Canada. ${ }^{5}$ Similarly, in China, the prevalence of childhood obesity steadily increased over a 25-year period (1985-2010) and was consistently higher among boys than girls aged $7-18 .{ }^{6}$ From 2000 to 2010 in Poland, the prevalence of both overweight and obesity in children aged 3-19 increased, with a greater prevalence in boys than girls. ${ }^{7}$

Despite the apparent sex-differences in childhood obesity prevalence, there has been limited discussion of the possible reasons and implications of this difference. Sex-based and gender-based research may elucidate important findings that may otherwise not be observed. ${ }^{8}$ Sex is a biological construct including chromosomes, genitalia and hormones, while gender is a sociocultural construct including adopted or imposed social norms, behaviours, identities and expectations in society. ${ }^{8}$ The United States National Institutes of Health and the Canadian Institutes for Health Research encourage researchers to consider the effects of both sex 


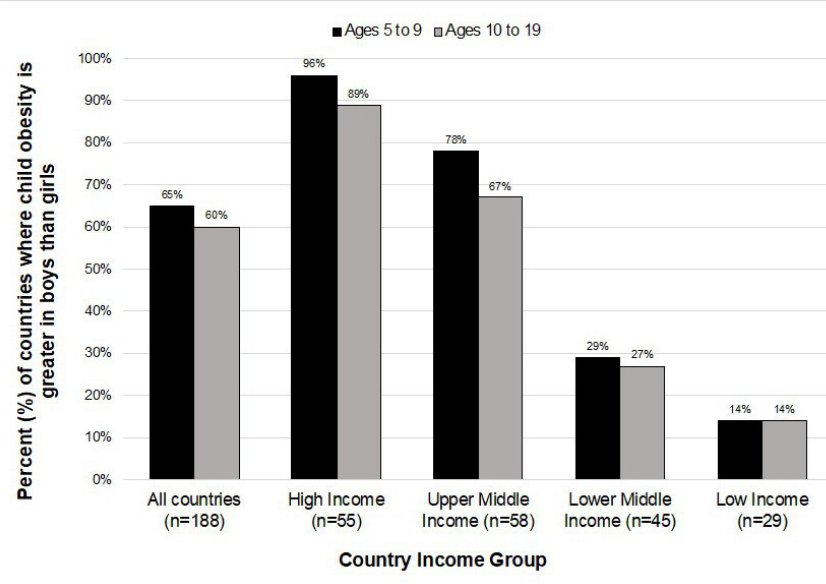

Figure 1 Percent of countries with higher obesity prevalence in boys than girls by age group, and country income group (created using data from the 2019 Atlas of Childhood Obesity).

and gender throughout the research process. ${ }^{9}{ }^{10}$ Here, we propose several hypotheses that may warrant future studies and further research on childhood obesity.

\section{SEX DIFFERENCES}

Differences in prevalence of childhood obesity may be driven in part by biological influences. Biological differences in body composition between sexes emerge quite early on, during the fetal and postnatal periods. ${ }^{11}$ Female fetuses have significantly smaller late-second and third trimesters fetal growth measurements than males. ${ }^{11}$ Following birth, females generally have greater fat mass and less fat-free mass, which is in turn associated with less energy intake and lower calorie needs for females than males. ${ }^{12}{ }^{13}$ Sex steroid hormones are associated with differences in body composition in children and youth. ${ }^{14} 15$ Further, females also exhibit higher circulating concentrations of leptin, a hormone that suppresses appetite and promotes energy utilisation. ${ }^{16}{ }^{17}$ Increased levels of serum leptin are a function of fat mass and directly proportional to levels of adiposity. ${ }^{1617}$ Reference values for serum leptin concentrations according to sex, BMI and pubertal status are established. ${ }^{16}$ Sex differences in leptin levels have also been examined through studies showing the strong influence of sex steroid hormones on leptin expression and secretion on the level of the adipocyte. ${ }^{18} 19$ For example, higher concentrations of androgens in males have a suppressive effect which is responsible for lower leptin serum concentrations compared with females. ${ }^{16}{ }^{18}$ Other research has identified different genes or subsets of genes that contribute to the variance in body composition in males and females, indicating that sexually dimorphic presentations of childhood obesity may also be explained by genetic differences. ${ }^{12}$ Another biological factor that may be important to consider is brown adipose tissue (BAT), as it is speculated that decreased BAT might be implicated in the development of obesity. ${ }^{20}$ Several studies in adult patients have found BAT to be more prevalent in women than men, but the association in children is less understood..$^{20}$

\section{GENDER DIFFERENCES}

Differences in obesity prevalence between boys and girls may also be driven in part by sociocultural influences. Some evidence suggests that girls, particularly those in higher income countries, may prefer foods that are lower in energy and nutrient-dense, such as fruits and vegetables, whereas boys tend to consume more meat and calorie-dense foods. ${ }^{21-24}$ Girls may also frequently report higher levels of weight-related concerns compared with boys, including desire to lose weight, feelings of guilt over eating too much and lower self-esteem. ${ }^{21}{ }^{24}$ These differences are likely a result of gender-based stereotypes as a feminine identity is typically characterised by eating smaller portions and preferring healthier options to maintain appearance, while a masculine eating identity is characterised by feeling full, with a focus on optimising physical performance. ${ }^{25}$ The greater emphasis on 'thinness' as a cultural ideal in girls may also lead to differences in parental nurturing, feeding practices and attitudes. ${ }^{25} 26$ Studies have shown that parents tend to be more concerned about weight status in their daughters than sons, while sons are usually encouraged to eat more. ${ }^{25}{ }^{26}$ Aside from dietary influences, additional societal conditions may also influence gender differences in obesity prevalence. For example, one study found significant interactions between gender and both presence of medical conditions and receipt of social assistance on child BMI. ${ }^{27}$ Significant gender differences in sleeping, physical activity and television-watching behaviours, have also been observed: school-aged girls have shorter sleep duration, engage in less physical activity and watch less television than boys. ${ }^{21} 2829$ Interestingly, both shorter sleep duration and less physical activity are risk factors for obesity ${ }^{29}{ }^{30}$ which is inconsistent with the observation that girls tend to have lower obesity prevalence than boys in high and upper middle-income countries.

\section{APPLYING SEX-BASED AND GENDER-BASED ANALYSIS TO CHILDHOOD OBESITY STUDIES MAY YIELD IMPORTANT INSIGHTS}

Improved sex-based and gender-based analysis can elucidate why obesity prevalence is greater among boys than girls. Currently, most studies control for sex (eg, by adjusting for sex in a multivariable regression model) rather than understanding if there are sex or gender differences. ${ }^{31}$ Presenting results without sex or gender analysis may mask useful information, limit practical applications and obscure differences that may help explain the distribution of obesity. For example, some literature has suggested that the patterning of childhood obesity according to certain risk factors, such as ethnicity or socioeconomic status, may differ for males 
and females. ${ }^{32} 33$ In this case, it would be important to both report overall prevalence of obesity and also analyse the sociodemographic patterning of obesity separately for boys and girls. Of the studies that have investigated differences, most focus on biological sex (male vs female) only. A first step to improved sex-based and gender-based analysis may be improved measurement of important genderrelated variables, including context variables (ie, cultural norms, expectations and the relative position of genders in society), ${ }^{34}$ individual variables (ie, gender socialisation, gender role and gender ideology) ${ }^{36}$ and the degree to which an individual conforms to or challenges cultural gender norms. A priori analysis planning can determine sufficient sample size for stratified analyses including sexbased and gender-based variables.

\section{OBESITY PREVENTION AND TREATMENT STRATEGIES MAY BE IMPROVED BY CONSIDERING SEX AND GENDER}

Addressing both sex and gender differences are important for the development of effective obesity prevention interventions. Upstream influences on childhood obesity begin very early in the life course and are present at multiple levels, including the family and community. Therefore, it may be valuable to consider the impact of sex and gender by shifting the prevention focus beyond individual children's body weight as the outcome. Family-based interventions to improve parenting style and the home food environment have been considered in general, but not with a gender-specific or sex-specific focus. There is also some evidence that school-based interventions to prevent childhood obesity vary in effectiveness according to gender. ${ }^{37}$ To promote healthy weight-related beliefs and behaviours among boys and girls, obesity prevention interventions should be sensitive to these differences and aim to shift gendered eating behaviours and weight perceptions via population-level strategies. Prevention efforts could also include targeted sex-based and genderbased programmes aimed at teaching parents about healthy weights and feeding patterns for children.

\section{CONCLUSION AND NEXT STEPS TO FURTHER THE RESEARCH AGENDA}

There is an urgent need to understand the observed differences in the prevalence of childhood obesity in boys and girls worldwide. In high and upper middle-income countries, boys tend to have greater obesity prevalence than girls, yet the possible reasons and implications of this difference are not well understood. Little is known about gender-specific social norms related to eating habits and body habitus in lower income countries. More research is therefore needed to better understand the differences in sex and gender-based patterns in obesity. Improved measurement of gender, and application of sex-based and gender-based analysis to childhood obesity studies, may generate valuable insights for both researchers and policymakers to tackle this major public health concern.
Contributors BS and LNA developed the research idea and drafted the manuscript. $\mathrm{KTC}, \mathrm{AF}$ and $\mathrm{CB}$ provided original ideas and reviewed the manuscript. All authors read and approved the final version.

Funding The authors have not declared a specific grant for this research from any funding agency in the public, commercial or not-for-profit sectors.

Competing interests None declared.

Patient consent for publication Not required.

Provenance and peer review Not commissioned; externally peer reviewed.

Open access This is an open access article distributed in accordance with the Creative Commons Attribution Non Commercial (CC BY-NC 4.0) license, which permits others to distribute, remix, adapt, build upon this work non-commercially, and license their derivative works on different terms, provided the original work is properly cited, appropriate credit is given, any changes made indicated, and the use is non-commercial. See: http://creativecommons.org/licenses/by-nc/4.0/.

ORCID iDs

Bindra Shah http://orcid.org/0000-0001-6463-1846

Laura N Anderson http://orcid.org/0000-0002-6106-5073

\section{REFERENCES}

1 Lobstein T, Brinsden H. Atlas of childhood obesity. World Obesity Federation, 2019.

2 Hruby A, Hu FB. The epidemiology of obesity: a big picture. Pharmacoeconomics 2015;33:673-89.

3 Abarca-Gómez L, Abdeen ZA, Hamid ZA, et al. Worldwide trends in body-mass index, underweight, overweight, and obesity from 1975 to 2016: a pooled analysis of 2416 population-based measurement studies in 128.9 million children, adolescents, and adults. Lancet 2017;390:2627-42

4 Rodd C, Sharma AK. Recent trends in the prevalence of overweight and obesity among Canadian children. CMAJ 2016;188:E313-20.

5 Carsley S, Pope El, Anderson LN, et al. Temporal trends in severe obesity prevalence in children and youth from primary care electronic medical records in Ontario: a repeated cross-sectional study. CMAJ Open 2019;7:E351-9.

6 Song Y, Wang H-J, Dong B, et al. 25-year trends in gender disparity for obesity and overweight by using who and IOTF definitions among Chinese school-aged children: a multiple cross-sectional study. BMJ Open 2016;6:e011904.

7 Kowal M, Woronkowicz A, Kryst Łukasz, et al. Sex differences in prevalence of overweight and obesity, and in extent of overweight index, in children and adolescents (3-18 years) from Kraków, Poland in 1983, 2000 and 2010. Public Health Nutr 2016;19:1035-46.

8 Johnson JL, Greaves L, Repta R. Better science with sex and gender: facilitating the use of a sex and gender-based analysis in health research. Int J Equity Health 2009;8:14.

9 Government of Canada Cl of HR. How to integrate sex and gender into research - CIHR, 2018. Available: http://www.cihr-irsc.gc.ca/e/ 50836.html [Accessed 19 Nov 2019].

10 Office of Research on Women's Health. Sex \& gender. Available: https://orwh.od.nih.gov/sex-gender [Accessed 19 Nov 2019].

11 Broere-Brown ZA, Baan E, Schalekamp-Timmermans S, et al. Sexspecific differences in fetal and infant growth patterns: a prospective population-based cohort study. Biol Sex Differ 2016;7:65.

12 Wisniewski AB, Chernausek SD. Gender in childhood obesity: family environment, hormones, and genes. Gend Med 2009;6:76-85.

13 Campbell MK, Biological CMK. Biological, environmental, and social influences on childhood obesity. Pediatr Res 2016;79:205-11.

14 Wells JCK. Sexual dimorphism of body composition. Best Pract Res Clin Endocrinol Metab 2007;21:415-30.

15 Veldhuis JD, Roemmich JN, Richmond EJ, et al. Endocrine control of body composition in infancy, childhood, and puberty. Endocr Rev 2005;26:114-46.

16 Blum WF, Englaro P, Hanitsch S, et al. Plasma leptin levels in healthy children and adolescents: dependence on body mass index, body fat mass, gender, pubertal stage, and testosterone. J Clin Endocrinol Metab 1997;82:2904-10.

17 Garnett SP, Högler W, Blades B, et al. Relation between hormones and body composition, including bone, in prepubertal children. Am J Clin Nutr 2004;80:966-72.

18 Wabitsch M, Blum WF, Muche R, et al. Contribution of androgens to the gender difference in leptin production in obese children and adolescents. J Clin Invest 1997;100:808-13.

19 Elbers JM, Asscheman H, Seidell JC, et al. Reversal of the sex difference in serum leptin levels upon cross-sex hormone 
administration in transsexuals. J Clin Endocrinol Metab 1997:82:3267-70.

20 Karastergiou K, Smith SR, Greenberg AS, et al. Sex differences in human adipose tissues - the biology of pear shape. Biol Sex Differ 2012;3:13.

21 Wang VH, Min J, Xue H, et al. What factors may contribute to sex differences in childhood obesity prevalence in China? Public Health Nutr 2018;21:2056-64.

22 Caine-Bish NL, Scheule B. Gender differences in food preferences of school-aged children and adolescents. J Sch Health 2009;79:532-40.

23 Wouters EJ, Larsen JK, Kremers SP, et al. Peer influence on snacking behavior in adolescence. Appetite 2010;55:11-17.

24 Bauer KW, Larson NI, Nelson MC, et al. Socio-environmental, personal and behavioural predictors of fast-food intake among adolescents. Public Health Nutr 2009;12:1767-74.

25 Keller K, Kling S, Fuchs B, et al. A biopsychosocial model of sex differences in children's eating behaviors. Nutrients 2019;11:682.

26 Xie X, Wu H, Lee T, et al. Gender differences in home environments related to childhood obesity in Nanchang, China. Child Obes 2014:10:416-23.

27 Gonzalez A, Boyle MH, Georgiades K, et al. Childhood and family influences on body mass index in early adulthood: findings from the Ontario child health study. BMC Public Health 2012;12:755.

28 Munakata $\mathrm{H}$, Sei M, Ewis AA, et al. Prediction of Japanese children at risk for complications of childhood obesity: gender differences for intervention approaches. J Med Invest 2010;57:62-8.
29 Pietiläinen KH, Kaprio J, Borg P, et al. Physical inactivity and obesity: a vicious circle. Obesity 2008;16:409-14.

30 Patel SR, Hu FB. Short sleep duration and weight gain: a systematic review. Obesity 2008;16:643-53.

31 Sweeting HN. Gendered dimensions of obesity in childhood and adolescence. Nutr J 2008;7:1

32 Yang $\mathrm{Z}$, Phung $\mathrm{H}$, Hughes A-M, et al. Trends in overweight and obesity by socioeconomic status in year 6 school children, Australian Capital Territory, 2006-2018. BMC Public Health 2019;19:1512.

33 Skinner AC, Ravanbakht SN, Skelton JA, et al. Prevalence of obesity and severe obesity in US children, 1999-2016. Pediatrics 2018;141:e20173459.

34 Zentner M, Mitura K. Stepping out of the caveman's shadow: nations' gender gap predicts degree of sex differentiation in mate preferences. Psychol Sci 2012;23:1176-85

35 Johns MM, Beltran O, Armstrong HL, et al. Protective factors among transgender and gender variant youth: a systematic review by Socioecological level. J Prim Prev 2018;39:263-301.

36 Smiler AP, Epstein M. Measuring gender: Options and issues. In: Handbook of gender research in psychology, vol 1: gender research in general and experimental psychology. Springer Science + Business Media, 2010: 133-57.

37 Brown T, Summerbell C. Systematic review of school-based interventions that focus on changing dietary intake and physical activity levels to prevent childhood obesity: an update to the obesity guidance produced by the National Institute for health and clinical excellence. Obes Rev 2009;10:110-41. 